\title{
Energy efficient route planning for electric vehicles with special consideration of the topography and battery lifetime
}

\author{
Theresia Perger (D) - Hans Auer
}

Received: 22 July 2019 / Accepted: 28 August 2020 / Published online: 25 September 2020

(C) The Author(s) 2020

\begin{abstract}
In contrast to conventional routing systems, which determine the shortest distance or the fastest path to a destination, this work designs a route planning specifically for electric vehicles by finding an energy-optimal solution while simultaneously considering stress on the battery. After finding a physical model of the energy consumption of the electric vehicle including heating, air conditioning, and other additional loads, the street network is modeled as a network with nodes and weighted edges in order to apply a shortest path algorithm that finds the route with the smallest edge costs. A variation of the Bellman-Ford algorithm, the Yen algorithm, is modified such that battery constraints can be included. Thus, the modified Yen algorithm helps solving a multi-objective optimization problem with three optimization variables representing the energy consumption with (vehicle reaching the destination with the highest state of charge possible), the journey time, and the cyclic lifetime of the battery (minimizing the number of
\end{abstract}

T. Perger $(\bowtie) \cdot H$. Auer

Institute of Energy Systems and Electrical Drives, Energy

Economics Group (EEG), TU Wien, Gusshausstrasse 25-29

E370-3, 1040, Wien, Austria

e-mail: perger@eeg.tuwien.ac.at

H. Auer

e-mail: auer@eeg.tuwien.ac.at charging/discharging cycles by minimizing the amount of energy consumed or regenerated). For the optimization problem, weights are assigned to each variable in order to put emphasis on one or the other. The route planning system is tested for a suburban area in Austria and for the city of San Francisco, CA. Topography has a strong influence on energy consumption and battery operation and therefore the choice of route. The algorithm finds different results considering different preferences, putting weights on the decision variable of the multi-objective optimization. Also, the tests are conducted for different outside temperatures and weather conditions, as well as for different vehicle types.

Keywords Energy efficiency · Electric vehicles . Route planning $\cdot$ Yen algorithm $\cdot$ Multi-objective optimization - Battery lifetime

\section{Nomenclature}

\section{Vehicle parameters}

$m$

$c_{w}$

A

SoC

$w / h$

$v$
Mass

Drag coefficient

Cross-sectional area

State of charge of the battery Width/height

Velocity 


\section{Road parameters}

$s$

$q$

$\alpha$

Length of a road section

Slope of a road section in \%

Slope of a road section in rad

\section{External parameters}

$T$

$g$

$\rho$

$f_{R}$

\section{Efficiencies}

$\begin{array}{ll}\eta_{\mathrm{d}} & \text { Final drive } \\ \eta_{\mathrm{m}} / \eta_{\mathrm{g}} & \text { Motor/generator } \\ \eta_{\text {inv }} & \text { DC-AC inverter } \\ \eta_{\text {acc }} & \text { Accessories } \\ \eta_{\text {hc }} & \text { Heating and cooling } \\ \eta_{\text {cha }} / \eta_{\text {dis }} & \text { Battery charging/discharging }\end{array}$

Topography data

$\begin{array}{ll}R_{\text {earth }} & \text { Earth radius } \\ \phi / \psi & \text { Coordinates in longitude/latitude } \\ \Delta x / \Delta y & \text { Distances } \\ \Delta z & \text { Height difference }\end{array}$

\section{Energy consumption}

$\begin{array}{ll}F_{\text {roll }} & \text { Rolling resistance } \\ F_{\text {air }} & \text { Air resistance } \\ F_{\text {grad }} & \text { Gradient resistance } \\ F_{\text {drive }} & \text { Driving force } \\ P_{\text {drive }} & \text { Power for driving } \\ P_{\text {heat }} & \text { Power for heating } \\ E_{\text {drive }} & \text { Energy for driving } \\ E_{\text {regen }} & \text { Regenerative energy from driving } \\ E_{\text {acc }} & \text { Energy consumption for the } \\ E_{\mathrm{hc}} & \text { accessories } \\ E_{\text {out }} / E_{\text {in }} & \text { Energy for heating and cooling }\end{array}$

\section{Multi-objective optimization}

$a$

$\gamma / \delta$

$f_{i}^{(k)} / g_{i}^{(k)} / h_{i}^{(k)}$

$d_{i, j} / t_{i, j} / a_{i, j}$

$E_{\min } / T_{\min } / A_{\min }$
Outside temperature

Air density

Rolling resistance coefficient

Final drive

Accessories

Battery charging/discharging

Earth radius

Distances

difference

Air resistance

Gradient resistance

Minimum battery capacity factor

Weights for multi-obj.

optimization

Costs to node $i$ ( $k$ th iteration)

Edge costs from $i$ to $j$

Optimization results

\section{Introduction}

Combustion engine driven cars have been dominating our world for more than a century. With global warming concerns (Gota et al. 2019) and increasingly stringent environmental policies ahead, vehicles with electric motors could be part of the solution, a precondition being that electrical power comes from renewable sources. In addition, further challenges come up with this new technology option in transportation. Despite higher efficiency than combustion engines, the task to store energy in the vehicle is still challenging. The battery offers a much more limited range compared with conventional cars. Moreover, recharging an electric vehicle is more time-consuming than refilling a tank. This leads to a more complex trip planning with an electric vehicle. A good advice is to identify the location of charging stations beforehand and to plan the route accordingly. Energy consumption can vary significantly depending on the path chosen. This work elaborates on optimal route planning to a desired destination while considering the special characteristics of electric vehicles. The main focus lies on improving the battery lifetime, as well as minimizing energy consumption and journey time while taking into account impacts of topography.

The first objective of this work is to find a route from a starting to a destination point with the least amount of energy used. This task is expanded such that it is possible to calculate the shortest journey time as well as the best route to maximize battery lifetime. Those route planning options are combined into a weighted multi-objective optimization problem. Shortest path algorithms are used in networks consisting of nodes, edges, and edge costs to solve the optimization problem. With the help of these algorithms, it is possible to find the path from one node to another with the smallest edge costs. Based on a model of the electric vehicle, which describes the physics of different driving modes, the energy consumption and travel time are approximated. It includes the energy required for driving as well as additional loads for air conditioning and other accessories. The model also considers engine operation as either a motor or as a generator and thus respects regenerative energy. 
The following "State of the art" section gives an overview of relevant work covering this topic. The "Methodology" section explains the model, which is used to calculate the vehicle's energy consumption, and the impact additional loads and efficiencies have on the vehicle. Furthermore, the street network model, the shortest path algorithm, and the multiobjective optimization are explained. The "Results" section presents the results of the optimization algorithm tested for an urban as well as a suburban area. In addition, a sensitivity analysis investigates the effects of temperature and different vehicle models from different manufacturers. The "Conclusion and outlook" section presents conclusions and elaborates on still open questions in this field of research.

\section{State of the art}

Creating an optimal route planning system for electric vehicles is multi-disciplinary and requires profound knowledge of electric vehicles, batteries, route planning algorithms, and dynamic optimization.

Modeling electric vehicles Energy efficiency and battery conservation are the main goals of the proposed optimal route planning system. Therefore, the electric vehicle is described based on a physical model in order to enable calculation of the energy consumption. In this context, one special characteristic of electric vehicles is the ability to regenerate energy from braking or driving downhill. In Lv et al. (2015) the energy flow from regenerative braking is modeled in detail. Another detailed model of the vehicle's energy consumption is presented in Yi and Bauer (2017). The goal is to find a high-resolution powertrain efficiency estimation. The energy consumption is described by the physical forces acting on the moving vehicle. A similar concept can be found in Maia et al. (2011), where an energy consumption simulator is presented. An alternative approach to estimate the energy consumption of an electric vehicle is found in Hayes et al. (2011), where a range estimator is created by using different drive cycles, which are originally based on combustion engines and then adapted for electric vehicles. However, the approach in Hayes et al. (2011) avoided modeling the physics of an electric vehicle.
Battery lifetime in electric vehicles Having batteries as an energy storage in vehicles comes along with many new challenges (see, e.g., Rizoug et al. (2018)) compared with cars with conventional combustion engines. Apart from their costly production, batteries have a limited lifetime. According to Li et al. (2017), by 2020 nearly one million electric vehicle battery packs will be "retired" in the USA alone, meaning that they cannot be used in electric vehicles anymore. This happens when (i) the battery only provides less than $80 \%$ of the original capacity and maximum power, or (ii) there are functional failures occurring. Several models to describe the battery degradation can be found in Pelletier et al. (2017), where cycle aging as well as calendar aging mechanisms are considered. Fernández et al. (2013) propose an optimal charging energy management that minimizes the degradation of the battery as a function of temperature and depth of discharge. In Wang et al. (2016) a battery degradation model of the cycle losses is used, which is linear dependent in cumulative current throughput, but quadratic in temperature. One interesting result is found in Peterson et al. (2010), where capacity fade of commercial Li-ion batteries caused by driving and vehicle-to-grid usage is studied. Battery degradation was found to be related to the amount of energy processed in the battery, while the depth of discharge has less effects on the battery lifetime. The importance of methods to increase the battery lifetime corresponds with the work in Hawkins et al. (2012), where it is shown that replacing a battery frequently may harm the environment and increases the risk of toxicity (e.g., for humans and freshwater) and metal depletion impacts.

Route planning algorithms Route planning problems are typically solved by applying shortest path algorithms. The Dijkstra algorithm (Dijkstra 1959) is a very efficient method to work with weighted graphs and is widely used in network theory. A Dijkstrabased speed-up technique for constrained shortest path problems is applied in Storandt (2012), where route planning is conducted for bicycles. The Dijkstra algorithm is also applied in Song et al. (2015). In that work, route planning in urban areas with influences of traffic is considered. The Bellman-Ford (Bellman 1958) algorithm has a higher complexity than Dijkstra, but can be used in networks with negative edge costs, which is useful for route planning for electric 
vehicles. Despite its high complexity, the BellmanFord algorithm works well with street networks. The Yen algorithm (Yen 1970) is based on Bellman-Ford, but it is generally able to solve the shortest path problem faster than Bellman (1958).

Route planning for electric vehicles It is mentioned in Neaimeh et al. (2013) that many people, who tested electric vehicles, experience so-called range anxiety. It turns out that many drivers would change their driving behavior and especially their route-choices to the destination. In order to find an optimal route that can extend the range of the vehicle, Dijkstra's shortest path algorithm is applied. The goal is not to simply find the energy-minimal route, but also to help with range anxiety, making drivers feel more comfortable with e-mobility. In Nunzio and Thibault (2017) a range estimation for online use is created, which is based on calculating the energy-optimal route. The vehicle's energy consumption is modeled including influences of traffic and with a shortest path algorithm (Bellman-Ford) the range can be estimated. In Storandt and Funke (2012) battery switch station are included in the network and a modification of Dijkstra's algorithm is used. This modification is done by using Johnson's shifting technique (see Johnson 1977) in order to include regenerated energy of the electric vehicle. In practice, battery switch stations are not established, but charging stations become increasingly visible. In Storandt et al. (2013), the approach is similar to Storandt and Funke (2012), but including charging stations instead of battery switch stations. It is also proposed to work on a multi-criteria optimization that includes the journey time and a maximum number of recharging events.

The present work implements a multi-objective optimization approach determining a path that seeks to meet best the drivers' requirements. In detail, the optimization algorithm uses weighting factors on these three optimization variables:

(i) Energy consumption: The electric vehicle should reach the destination with the highest possible state of charge of the battery.

(ii) Time: The journey time should be as short as possible.

(iii) Battery lifetime: In order to increase the battery lifetime of the electric vehicle, the number of charging and discharging cycles should be as small as possible, therefore the cumulated energy flow should be minimized.

The goal of this paper is to include the drivers' preferences in a very flexible way. For example, the drivers can choose a single-objective optimization of either of the above-mentioned variables, or give equal weights to all three. Charging stations for electric vehicles are not included in this work.

\section{Methodology}

Optimization problem

The objective of this work is to design a route planning system for electric vehicles in order to optimize the battery lifetime, energy consumption, and journey time. A weighted multi-objective optimization approach is used to prioritize one aspect or the other.

\section{Flowchart}

To achieve the objective of this work-finding the weighted optimal path to a desired destination with an electric vehicle-it is important to have a model describing the energy consumption of the electric vehicle and the street network. Then, shortest path algorithms can be used for optimization. A flow chart (see Fig. 1) presents an overview of this optimization problem. At first, a starting and a destination point have to be defined. Then, it is necessary to have a road network that includes topography information. Each road section has a defined length $s$, a velocity $v$, and a slope $q$ in $\%$, calculated from the topography information. The next step is to define the vehicle parameters. The initial state of charge of the battery $S o C_{\text {init }}$ and its maximum capacity $S_{o} C_{\max }$ are necessary, as well as the mass $m$, the drag coefficient $c_{w}$, and the cross-sectional area $A$ of the vehicle. When having information on the outside temperature $T$, all parameters are available for the calculation of the energy consumption model of the electric vehicle and the journey time on all the possible roads of the network.

As this work formulates an optimization problem with constraints, the boundary conditions have to be 
Fig. 1 Flowchart of the optimization problem

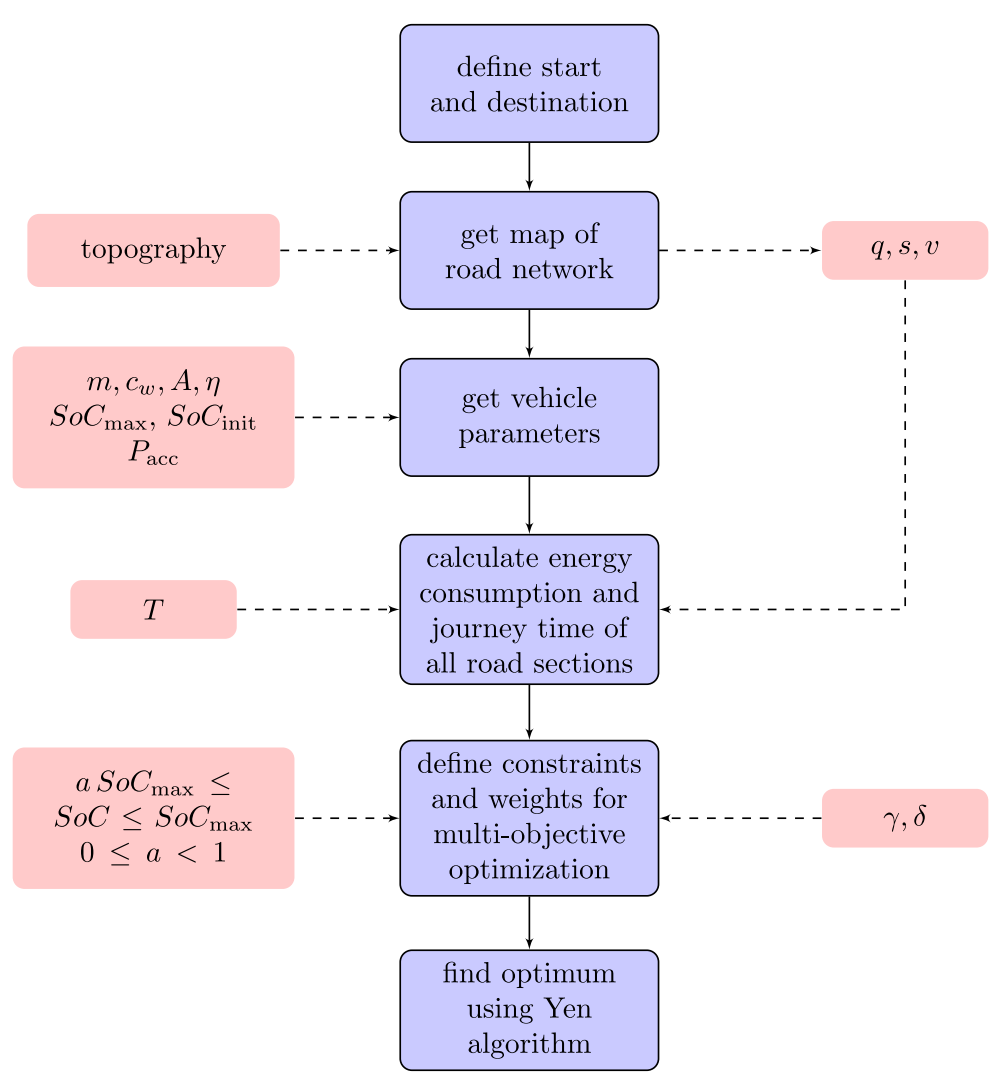

defined. Naturally, the state of charge of the battery $S o C$ cannot be negative or above the maximum capacity. In the interest of the vehicle owner, the $S o C$ should not fall below a certain minimum capacity, because deep discharge can decrease battery lifetime. A factor $a, 0 \leq a<1$, is added to the optimization problem, such that the constraint equation becomes

a $S o C_{\max } \leq S o C \leq S o C_{\max }$.

The task will be extended to a multi-objective optimization with the variables energy, time, and battery lifetime. The factors $\gamma$ and $\delta$, with $\gamma+\delta \leq 1$, are used to give weights to the optimization variables. The last step is to apply a shortest path algorithm.

Modeling the energy consumption

\section{Energy consumption for driving}

We start with the calculation of the energy consumption of an electric vehicle for driving. The basic principles of the calculations are similar to conventional vehicles. The driving force $F_{\text {drive }}$ is calculated as the sum of the rolling resistance $F_{\text {roll }}$, the air resistance $F_{\text {air }}$, and the gradient resistance $F_{\text {grad }}$, while other factors are neglected for simplicity:

$$
\begin{aligned}
F_{\text {drive }} & =F_{\text {roll }}+F_{\text {air }}+F_{\text {grad }} \\
& =m g f_{R} \cos (\alpha)+\frac{1}{2} \rho c_{w} A v^{2}+m g \sin (\alpha) .
\end{aligned}
$$

The next step is the calculation of the power resulting from the driving force

$P_{\text {drive }}(t)=F_{\text {drive }}(t) \cdot v(t)$,

and then finally

$E_{\text {drive }}=\int_{t_{1}}^{t_{2}} P_{\text {drive }}(t) \mathrm{d} t$,

for the energy required over a certain period of time $t_{1} \leq t \leq t_{2}$.

\section{Total energy consumption of the electric vehicle}

Apart from regenerative energy from braking or driving downhill, the battery is the only source of energy in electric vehicles. Other loads than driving must 
Fig. 2 Energy

flow-engine operates as a motor

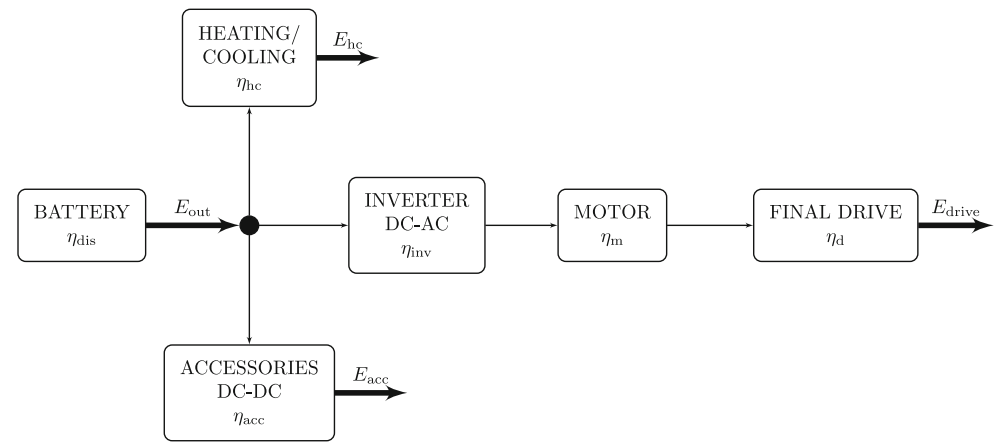

be covered by the battery as well. The major consumers are the heating and cooling, which are powered directly by the high voltage battery (around $400 \mathrm{~V}$ ), without any DC-DC converter (see Jeschke 2016). Other so-called accessory loads are headlights, fan, windshield wipers, rear window heating, and radio. These need low voltage (12 V) and therefore a DC-DC converter.

Figures 2 and 3 show the energy flow from the battery to the components of the vehicle with the engine operating as a motor or as a generator, respectively. $E_{\text {out }}$ is the energy the battery provides. $E_{\text {acc }}$ and $E_{\mathrm{hc}}$ represent the low voltage accessories, and the heating and cooling, respectively. $E_{\text {drive }}$ is used for driving, as in (5). The amount of energy $E$ that decreases the state of charge of the battery considering efficiency factors is

$E=\frac{1}{\eta_{\mathrm{dis}}}\left(\frac{1}{\eta_{\mathrm{d}} \eta_{\mathrm{m}} \eta_{\mathrm{inv}}} E_{\mathrm{drive}}+\frac{1}{\eta_{\mathrm{acc}}} E_{\mathrm{acc}}+\frac{1}{\eta_{\mathrm{hc}}} E_{\mathrm{hc}}\right)$,

if the engine operates as a motor (Fig. 2).

With electric vehicles, recharging the battery with regenerated energy from braking or driving downhill is possible. In this case, the driving power $P_{\text {drive }}$ in (4) is negative and the engine operates as a generator (see Fig. 3). There are two cases to distinguish: (i) the battery charges, only if the regenerated energy is sufficient to cover the accessory loads; (ii) the battery discharges, if the regenerated energy cannot cover all the accessory loads. The energy $E_{\text {out }}=-E_{\text {in }}$ can be calculated as

$E_{\text {out }}=-\eta_{\mathrm{d}} \eta_{\mathrm{g}} \eta_{\text {inv }} E_{\text {regen }}+\frac{1}{\eta_{\mathrm{acc}}} E_{\mathrm{acc}}+\frac{1}{\eta_{\mathrm{hc}}} E_{\mathrm{hc}}$,

and the total energy including charging and discharging efficiencies is

$E= \begin{cases}\frac{1}{\eta_{\text {dis }}} E_{\text {out }}, & \text { if } E_{\text {out }}>0 \\ \eta_{\text {charge }} E_{\text {out }}, & \text { if } E_{\text {out }}<0 \\ 0, & \text { if } E_{\text {out }}=0 .\end{cases}$

If the efficiency of the engine operating as a generator is the same as for a motor $\left(\eta_{\mathrm{m}}=\eta_{\mathrm{g}}\right)$, Eqs. (6) and (7) become

$E_{\text {out }}=\left(\frac{1}{\eta_{\mathrm{d}} \eta_{\mathrm{m}} \eta_{\text {inv }}}\right)^{\operatorname{sign}\left(E_{\text {drive }}\right)} E_{\text {drive }}+\frac{1}{\eta_{\mathrm{acc}}} E_{\mathrm{acc}}+\frac{1}{\eta_{\mathrm{hc}}} E_{\mathrm{hc}}$.

If the charging and discharging efficiencies of the battery are equal ( $\left.\eta_{\text {cha }}=\eta_{\text {dis }}\right)$, Eqs. (6) and (8) merge to one new equation

$E=\left(\frac{1}{\eta_{\text {dis }}}\right)^{\operatorname{sign}\left(E_{\text {out }}\right)} E_{\text {out }}$,
Fig. 3 Energy

flow-engine operates as a generator

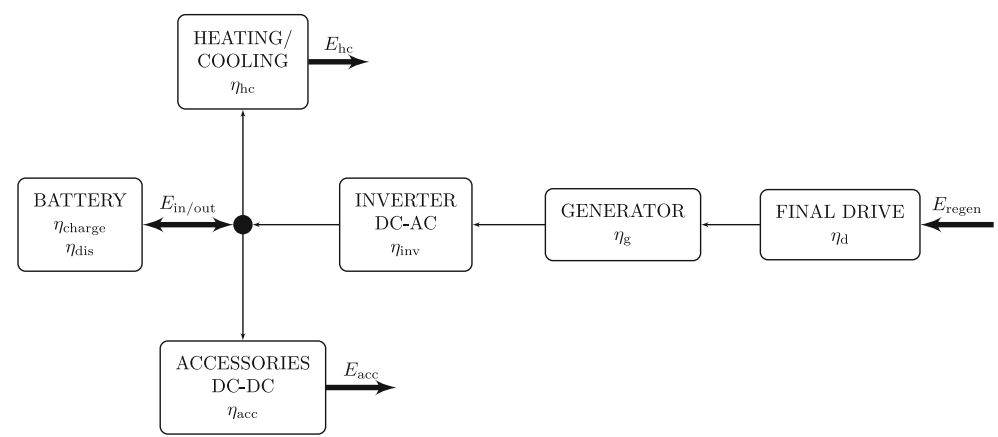


with $E_{\text {out }}$ as in Eq. (9).

Modeling the street network

The next task of the route planning is to model the real-life street network with its properties such as slope, distances, speed limits, and road type. In order to solve a shortest path problem, a specific structure of the street network is needed.

\section{Networks}

Networks consist of so-called nodes and edges. The nodes are connected with each other by edges, which can have assigned values called "edge weights" or "edge costs."

Nodes Nodes are the decision points of the network. Each node is connected to different nodes via edges. Some nodes are directly connected, others are only reachable by passing other nodes on the way. In the real-world street network, nodes are intersections of roads.

Edges Edges are the roads connecting the nodes. In this network model, the edges are split into straight sections with constant slope and constant speed limit.

Edge costs Networks have the purpose to express relations between the nodes. There are different ways to characterize such relations. The most elementary ones are a binary relations, describing whether there is a direct connection (an edge) or not. Edge costs can have physical meanings, such as the distance between nodes. A shortest path algorithm finds the path that cumulates the least amount of edge costs on its way. When the physical meaning of the edge costs is the energy consumption of an electric vehicle, the network becomes bidirectional. The main reason is the topography, as two nodes can be on different altitudes and, therefore, the required energy is different for both directions.

\section{Topography data}

Topography data is obtained from the "USGS Earth Explorer" website (https://earthexplorer.usgs.gov/), where geographical data is available for download. The file obtained from the USGS is a TIFF-file with
$3601 \times 3601$ pixel, containing a digital elevation map from the NASA Shuttle Radar Topography Mission (SRTM). It has a high spatial resolution of one arc-second for longitude (east-west) as well as for latitude (north-south). The height resolution is one meter. Since two adjacent pixels are one arc-second apart, the TIFF-file covers an area of one degree in longitude and one degree in latitude. For the calculations of the energy consumption of the electric vehicle, it is necessary to convert the distances given in degrees into distances in meters. The conversion is achieved by an approximation of the earth as a perfect sphere $^{1}$ with radius of $R_{\text {earth }}=6371 \mathrm{~km}=6371000 \mathrm{~m} . \phi_{1}$ and $\psi_{1}$ are the coordinates of a point in degree longitude and degree latitude, respectively. $\phi_{2}$ and $\psi_{2}$ are the coordinates of another point, and $\Delta \phi=\phi_{1}-\phi_{2}$ and $\Delta \psi=\psi_{1}-\psi_{2}$ are the distances between point 1 and point 2 (in degrees). The distances $\Delta x$ for longitude and $\Delta y$ for latitude in meters are converted using

$\Delta y=\frac{2 \pi R_{\text {earth }}}{360} \Delta \psi$,

and

$\Delta x=\frac{2 \pi R_{\text {earth }}}{360} \cos \left(\psi_{1} \pi / 180\right) \Delta \phi$.

It can be noticed that Eq. (12) depends on the coordinates of the latitude. At the equator, we have $\cos \left(\psi_{1} \pi / 180\right)=1$. The coordinate lines of the longitude converge when moving further away from the equator. Two places with a $\Delta \phi$ of $1^{\circ}$ at the equatorial line have a higher $\Delta x$ than two places with the same $\Delta \phi$ at another degree of latitude. The resolution of one arc-second of the map obtained from NASA means having a resolution of about $31 \mathrm{~m}$ north-south. It has to be mentioned that Eqs. (11) and (12) are only approximations of the real distances.

The next task is to calculate the slope of a road section that is straight and has a constant gradient. The difference in altitude $\Delta z$ between the start and the end point of the section, which is derived from the TIFF-file mentioned in the beginning of this section, is divided by the Euclidean distance between those points and multiplied by 100 in order to get the slope $q$ in $\%$ :

$q=100 \frac{\Delta z}{\sqrt{(\Delta x)^{2}+(\Delta y)^{2}}}$.

\footnotetext{
${ }^{1}$ Another approach to calculate the distance between two points on the surface of a sphere is, e.g., Haversine formula.
} 


\section{Street network}

After obtaining topographical data, the next step is to get an adequate network of roads containing the region of interest. One option is using "OpenStreetMaps," a big database for streets, roads, and paths. The use of "OpenStreetMaps" is problematic because many roads are missing labels with no possibility of distinguishing if they are footpaths, waterways, or streets. The same goes for data obtained from official government websites. Thus, a more simple approach is chosen. First, it is decided which roads should be part of the network. Only the main roads in the area of interest are included by taking coordinates of road sections. Some of the roads (edges) are a few kilometers long and split up into straight consecutive sections with a length varying from $50 \mathrm{~m}$ to a few hundred meters. For the purpose of testing the algorithm, this resolution is satisfying. For an advanced route planning system, a higher resolution would be needed. The coordinates of the start and end points of the road segments and the matching topography information obtained, the distances and height differences are calculated as explained in the "Topography data" section. This ensures each segment is straight and has a constant slope.

Optimization with a shortest path algorithm

The multi-objective optimization is solved by applying a shortest path algorithm. Shortest path algorithms use networks made of nodes and edges. The goal of shortest path algorithms is to find the path with the least amount of edge costs. In this case the edge costs represent the energy consumption, journey time, or the battery degradation. The "Yen algorithm" section explains the shortest path algorithm for one optimization variable. Then, the multi-objective optimization based on the shortest path algorithm is described in the "Multi-objective optimization" section.

\section{Yen algorithm}

A well-known shortest path algorithm is the BellmanFord algorithm (see Bellman 1958). An improved version of Bellman-Ford is the algorithm proposed by Jin Y. Yen (see Yen 1970). Both algorithms find the shortest paths from all nodes of the network to one specific destination node. The iterative search goes backwards, always starting from the destination node. In contrast, the state of charge of the battery $(S o C)$ is calculated forward, starting from the starting point. The constraints are violated if the $S o C$ exceeds the boundaries (see Eq. (1)). In addition, the goal for energy-optimal route planning is to arrive at the destination with the highest state of charge possible. The backwards iterations of the Yen algorithm are, therefore, not suitable for the optimization problem with $\mathrm{SoC}$ constraints. Hence, the following solution is introduced. Instead of computing all minimum paths to the destination, all minimum paths from the start are calculated. The principles of the Yen algorithm remain the same, but there are a few modifications. The algorithm is applied to find the energy-optimal path in a network with $N$ nodes in the following manner, starting with iteration 0 ,

$f_{i}^{(0)}=d_{1 i}$,

where $d_{1 i}$ are the edge costs from node 1 to node $i=2, \ldots, N$, representing the energy consumption required to travel from node 1 to $i$. The edge costs are calculated adding up the energy consumption $E_{l}$ (derived from Eq. (10)) of $M$ adjacent road sections:

$d_{i j}=\sum_{l=1}^{M} E_{l}$.

$f_{i}^{(k)}$ are the costs from node 1 , the start node, to node $i$ at iteration $k$. A distinction is made between odd and even numbered iterations. For odd iterations, the minimum is found using

$$
\begin{array}{r}
f_{i}^{(2 k-1)}=\min _{1 \leq j<i}\left(f_{j}^{(2 k-1)}+d_{j i}, f_{i}^{(2 k-2)}\right), \\
f_{1}^{(2 k-1)}=f_{1}^{(2 k-2),}
\end{array}
$$

with $i=2,3, \ldots, N$. For even iterations, the minimization is

$$
\begin{array}{r}
f_{i}^{(2 k)}=\min _{N \geq j>i}\left(f_{j}^{(2 k)}+d_{j i}, f_{i}^{(2 k-1)}\right), \\
f_{N}^{(2 k)}=f_{N}^{(2 k-1)},
\end{array}
$$

with $i=N-1, N-1, \ldots, 2$. For all iterations, the battery constraints are checked. If $\mathrm{SoC}>\mathrm{SoC}_{\max }$, the path is still feasible, but the current state of charge is set to the maximum capacity of the battery $(\mathrm{SoC}=$ $S o C_{\max }$ ), because no further charging is possible. The energy consumption $f_{j}^{(k)}+d_{j i}$ is adapted accordingly. If $S o C<a S o C_{\max }$, that path is considered unfeasible and $f_{i}^{(k)}$ is set to infinity, such that this path is neglected in all further calculations. If all minimum 
paths $f_{i}$ of iteration $k$ remain the same compared to the previous iteration $k-1$, the optimum is found:

$$
\boldsymbol{f}^{(k)}=\left[\begin{array}{c}
f_{1}^{(k)} \\
f_{2}^{(k)} \\
\vdots \\
f_{N}^{(k)}
\end{array}\right] \equiv\left[\begin{array}{c}
f_{1}^{(k-1)} \\
f_{2}^{(k-1)} \\
\vdots \\
f_{N}^{(k-1)}
\end{array}\right]=\boldsymbol{f}^{(k-1)}
$$

For time-optimal route planning, the optimum $g_{i}^{(k)}$ of each iteration $k$ is calculated having the edge costs $t_{j i}$ (see Eq. (A1.1))), the journey time from node $j$ to node $i$ (details in Appendix 1). Similarly, the optimum for the battery lifetime $h_{i}^{(k)}$ works with the edge costs $a_{j i}$ (see Appendix 2). $a_{j i}$ represents the absolute energy flow to and from the battery. The main difference between $d_{i j}$ and $a_{i j}$ concerns regenerative energy, which decreases the value $f_{i}^{(k)}$, but increases $h_{i}^{(k)}$, and therefore the Yen algorithm finds different minima.

\section{Multi-objective optimization}

The multi-objective optimization has three optimization variables: energy consumption of the vehicle, journey time, and cyclic lifetime of the battery. The algorithm applied for this task is based on the modified version of the Yen algorithm from the "Yen algorithm" section. The optimal path from the start node number 1 to all nodes $i$ is calculated in each iteration, taking into account all three variables and their weights, as well as the battery constraints. We start with iteration 0 , setting all three variables in the same manner:

$$
\begin{gathered}
f_{i}^{(0)}=d_{1 i}, \\
g_{i}^{(0)}=t_{1 i}, \\
h_{i}^{(0)}=a_{1 i} .
\end{gathered}
$$

The next step is to go into the details of the odd iterations. At first,

$$
\begin{gathered}
f_{1}^{(2 k-1)}=f_{1}^{(2 k-2)}, \\
g_{1}^{(2 k-1)}=g_{1}^{(2 k-2),} \\
h_{1}^{(2 k-1)}=h_{1}^{(2 k-2)}
\end{gathered}
$$

are set. Then, for the other nodes $i$, the energy-optimal path is calculated following Eq. (16). If at least one path is feasible, $E_{\min }=\left|f_{i}^{(2 k-1)}\right|$ is set and $T_{\min }$, the minimum in time, and $A_{\min }$, the smallest absolute energy consumption, are calculated according to
Eqs. (A1.4) and (A2.3), respectively. All three results are combined to multi-objective optimization with the weights $\gamma$ for energy, $\delta$ for time, and $1-(\gamma+\delta)$ for battery lifetime. The optimization problem solved for node $i=2,3, \ldots, N$ in iteration $2 k-1$ is:

$$
\begin{aligned}
& x_{i}^{(2 k-1)}=\min _{1 \leq j<i}\left(\gamma \frac{f_{j}^{(2 k-1)}+d_{j i}}{E_{\min }}+\delta \frac{g_{j}^{(2 k-1)}+t_{j i}}{T_{\min }}\right. \\
& +(1-(\gamma+\delta)) \frac{h_{j}^{(2 k-1)}+a_{j i}}{A_{\min }}, \\
& \gamma \frac{f_{j}^{(2 k-2)}}{E_{\min }}+\delta \frac{g_{j}^{(2 k-2)}}{T_{\min }} \\
& \left.+(1-(\gamma+\delta)) \frac{h_{j}^{(2 k-2)}}{A_{\min }}\right) \text {. }
\end{aligned}
$$

All energy costs are normalized by the factor $E_{\min }$, the journey time by $T_{\min }$, and the absolute energy by $A_{\text {min }}$. The normalized values equal to one at the optimum and greater than one for all the other paths. The deviation from the optimum is weighed with $\gamma, \delta$ and $1-(\gamma+\delta)$. After the minimum $x_{i}^{(2 k-1)}$ is found, the costs $f_{i}^{(2 k-1)}, g_{i}^{(2 k-1)}$, and $h_{i}^{(2 k-1)}$ are set according to the resulting multi-objective optimal path. For even iterations the situation is very similar. We start with

$$
\begin{gathered}
f_{N}^{(2 k)}=f_{N}^{(2 k-1)}, \\
g_{N}^{(2 k)}=g_{N}^{(2 k-1)}, \\
h_{N}^{(2 k)}=h_{N}^{(2 k-1)} .
\end{gathered}
$$

Then, for node $i$ the optimal values $E_{\min }, T_{\min }$, and $A_{\text {min }}$ are computed and multi-objective optimization is performed, iterating from $i=N-1$ to $i=2$ :

$$
\begin{aligned}
& x_{i}^{(2 k)}=\min _{N \geq j>i}\left(\gamma \frac{f_{j}^{(2 k)}+d_{j i}}{E_{\min }}+\delta \frac{g_{j}^{(2 k)}+t_{j i}}{T_{\min }}\right. \\
& +(1-(\gamma+\delta)) \frac{h_{j}^{(2 k)}+a_{j i}}{A_{\min }}, \\
& \gamma \frac{f_{j}^{(2 k-1)}}{E_{\min }}+\delta \frac{g_{j}^{(2 k-1)}}{T_{\min }} \\
& \left.+(1-(\gamma+\delta)) \frac{h_{j}^{(2 k-1)}}{A_{\min }}\right) \text {. }
\end{aligned}
$$

Reference values and assumptions

The proposed multi-objective optimization algorithm is implemented in MATLAB ${ }^{2}$ (MATLAB 2019) and two vehicles selected for testing are the Nissan

\footnotetext{
${ }^{2}$ The solving time for the tests in the "Suburban area: near Vienna, Austria" section is around $0.15 \mathrm{~s}$.
} 
Leaf, see data sheet (https://www.nissan.co.uk), and the Mitsubishi i-MiEV, see data sheet (https://www. mitsubishi-motors.com/en/products/\#search-models). All parameters necessary for the calculations are summarized in Table 1 . For the mass $m$, the curb weight of the vehicle, is combined with the weight of one person, the driver. The driver's mass is assumed to be $75 \mathrm{~kg}$. To calculate the air resistance $F_{\text {air }}$ according to Eq. (3), the cross-sectional area $A$ and the drag coefficient $c_{w}$ are necessary. If $A$ is not specified in the official data sheet, it may be estimated according to Haken (2013), knowing the width $w$ and height $h$ of the vehicle:

$A=0.81 \cdot w \cdot h$.

Accessory loads and efficiencies are obtained from the measurements in Geringer and Tober (2012). Some efficiency factors cannot be found in Geringer and Tober (2012), therefore they are assumed to be $100 \%$, except for the engine efficiency, which is assumed to be $90 \%$. The main differences between the two vehicle types are mass and the dimensions of height, weight, and drag coefficient.

\section{Results}

Suburban area: near Vienna, Austria

The street network covers the main roads of the Wienerwald area West of Vienna. The city of Vienna is excluded. The network has a total of 31 nodes and 41 edges. Different routes were tested with the multiobjective optimization algorithm. Planning a trip from Passauerhof (a in Fig. 4) to Maria Gugging (b) provides interesting results (see Fig. 4). There are two different solutions of the multi-objective optimization. The routes are:

(a) The first path, where the electric vehicle needs the least amount of energy, starts at Passauerhof, and passes through Katzlsdorf, Königstetten,

Table 1 Parameters of the two different electric vehicles

\begin{tabular}{|c|c|c|c|c|}
\hline & & Nissan leaf & Mitsubishi i-MiEV & \\
\hline \multicolumn{5}{|l|}{ Dimensions } \\
\hline Curb weight & & 1516 & 1090 & $\mathrm{~kg}$ \\
\hline Mass with driver & $m$ & 1591 & 1165 & $\mathrm{~kg}$ \\
\hline Drag coefficient & $c_{w}$ & 0.28 & 0.33 & - \\
\hline Width with mirrors & & 1967 & 1792 & $\mathrm{~mm}$ \\
\hline Width w/o mirrors & $w$ & 1770 & 1475 & $\mathrm{~mm}$ \\
\hline Height & $h$ & 1550 & 1610 & $\mathrm{~mm}$ \\
\hline Cross-sectional area & $A$ & 2.22 & 2.14 & $\mathrm{~m}^{2}$ \\
\hline \multicolumn{5}{|l|}{ Accessory loads } \\
\hline Heating & $P_{\text {heat }}$ & 90 & 95 & $\mathrm{~W} /{ }^{\circ} \mathrm{C}$ \\
\hline Cooling & $P_{\text {cool }}$ & 40 & 30 & $\mathrm{~W} /{ }^{\circ} \mathrm{C}$ \\
\hline Lights & $P_{\text {light }}$ & 48 & $38 / 127$ & $\mathrm{~W}$ \\
\hline Fan & $P_{\text {air }}$ & 62 & 48 & W \\
\hline \multicolumn{5}{|l|}{ Battery } \\
\hline Capacity & $S o C_{\max }$ & 24 & 16 & $\mathrm{kWh}$ \\
\hline \multicolumn{5}{|l|}{ Efficiencies } \\
\hline Drive & $\eta_{\mathrm{d}}$ & 1 & 1 & \\
\hline Motor & $\eta_{\mathrm{m}}$ & 0.90 & 0.90 & \\
\hline Inverter DC-AC & $\eta_{\text {inv }}$ & 0.96 & 0.91 & \\
\hline Battery & $\eta_{\text {dis }}$ & $0.90-0.96$ & $0.88-0.95$ & \\
\hline Accessories DC-DC & $\eta_{\mathrm{acc}}$ & 1 & 0.83 & \\
\hline Heating/cooling & $\eta_{\mathrm{hc}}$ & 1 & 1 & \\
\hline
\end{tabular}




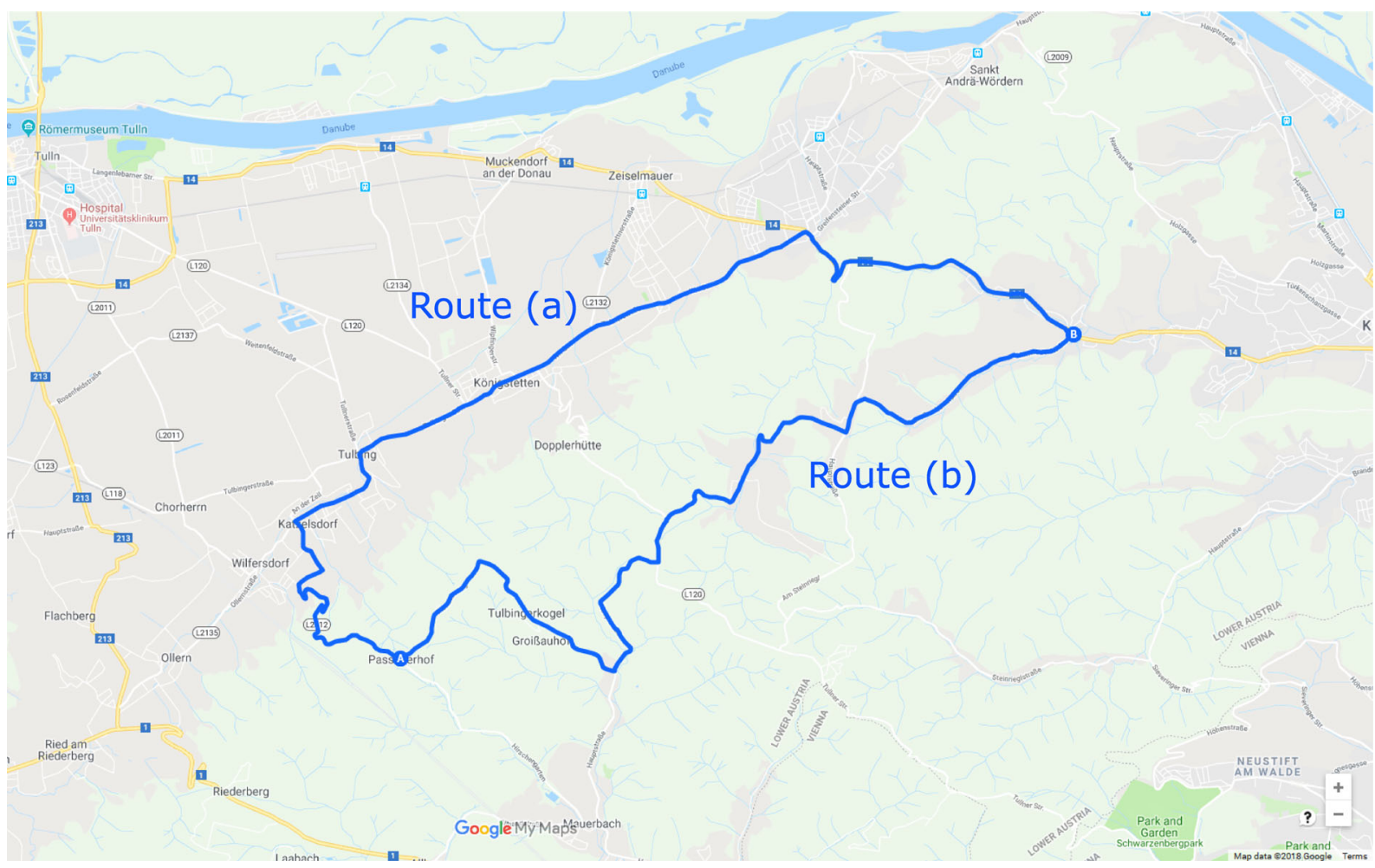

Fig. 4 Results from Passauerhof to Maria Gugging (edited screen-shot from Google Maps; Google and the Google logo are registered trademarks of Google LLC, used with permission)

and St. Andrä before it reaches the destination Maria Gugging (see Fig. 4).

(b) The other route (b) is both the fastest and the shortest route, but presents more variation in topography than (a), passing small villages such as Unterkirchen and Hintersdorf before reaching Maria Gugging (see Fig. 4).

Table 2 presents the solutions of the multi-objective optimization for various combinations of the weights.

Table 2 Results from passauerhof to maria gugging with nissan leaf at $20^{\circ} \mathrm{C}$

\begin{tabular}{lllllll}
\hline$\gamma / \delta$ & 0 & 0.2 & 0.4 & 0.6 & 0.8 & 1 \\
\hline 0 & (a) & (a) & (a) & (b) & (b) & (b) \\
0.2 & (a) & (a) & (a) & (b) & (b) & - \\
0.4 & (a) & (a) & (b) & (b) & - & - \\
0.6 & (a) & (a) & (b) & - & - & - \\
0.8 & (a) & (b) & - & - & - & - \\
1 & (a) & - & - & - & - & - \\
\hline
\end{tabular}

It can be noticed that combinations with small values of $\gamma$ and $\delta$ result in option (a). This route has less variation in topography than (b), as it can be seen in Figs. 5 and 6. If $\gamma$ and $\delta$ are small, the focus is on increasing the battery lifetime. In contrast to the optimization variable for energy consumption, where the regenerated energy has a negative sign and, therefore, helps minimizing the costs, the optimization variable representing the battery lifetime takes the absolute value of the energy. In this case, the regenerated energy counts the same way as the consumed energy. Therefore, driving downhill or braking increases the costs and is avoided by the optimization algorithm. A route with little elevation up and down is preferred. It can be seen in Fig. 6 that the absolute energy flow to and from the battery for route (a) is smaller than for route (b).

Combinations with a high value of $\delta$ lead to the fastest route (b). The difference in time is almost four minutes, which is a quarter of the total journey time of route (b). The difference in energy consumption is less significant (see Fig. 5). Choosing route (a), only 
Fig. 5 Topography and energy consumption on route (a) and route (b) from Passauerhof to Maria Gugging

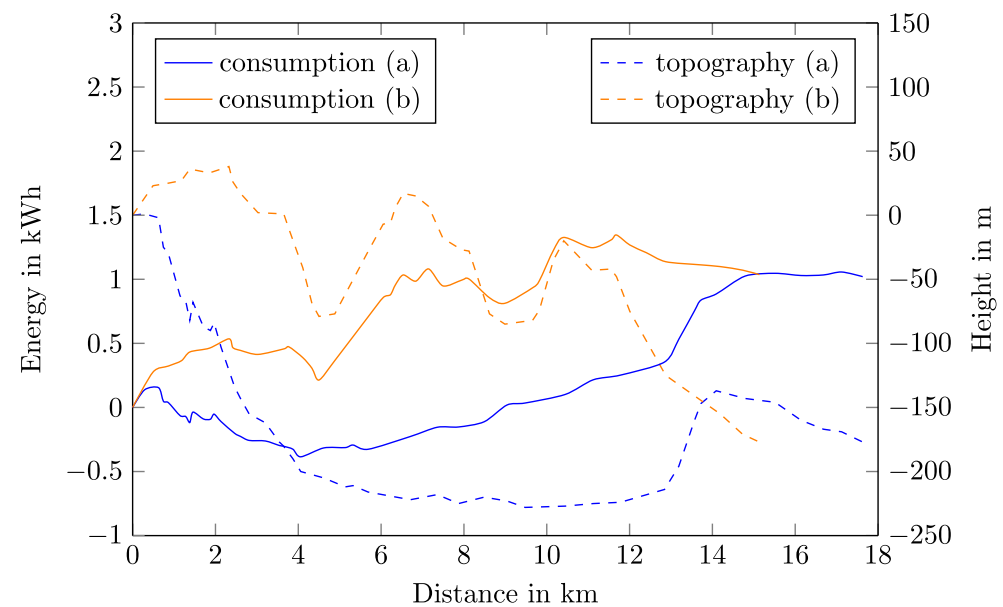

a few Watt-hours are saved. If the battery lifetime is neglected $(\gamma+\delta=1)$, a high value of $\gamma$ and a small $\delta$ lead to route (b), while only with $\gamma=1$, route (a) is chosen, because the savings in energy consumption are insignificant compared with the savings in journey time.

\section{Comparing under different temperatures}

The route planning system is also tested for different outside temperatures. During winter, the temperatures frequently fall below zero in Austria. Therefore, heating is necessary for the passengers in the vehicle. With the help of the measurements in Geringer and Tober (2012), it is possible to find a linear function of the Nissan Leaf's power demand for heating, which is $P_{\text {heat }}=90 \mathrm{~W} /{ }^{\circ} \Delta \mathrm{C}$. The energy consumption is expected to rise with lower temperatures, which may influence the results of the multi-objective optimiza- tion problem. Assuming an outside temperature of $T=-10^{\circ} \mathrm{C}$, we have

$P_{\text {hc }}=P_{\text {heat }}\left(T_{0}-T\right)=1800 \mathrm{~W}$,

with $T_{0}=20^{\circ} \mathrm{C}$. For the relatively short trip of around $20 \mathrm{~min}, 0.6 \mathrm{kWh}$ are used only for heating. In addition, battery (dis-)charging efficiency $\eta_{\text {dis }}$ is decreasing due to low temperatures (see Table 1). Table 3 shows the results for varying combinations of the optimization weights.

These results are not surprising considering that the energy consumption of all accessories, including heating and cooling, is time-dependent. This factor makes fast routes more attractive also when looking at energy-optimal route planning. In this case, route (a), which has less energy consumption at $20^{\circ} \mathrm{C}$, now requires more energy than route (b), making route (b) the most energy and time efficient route at temperatures of $-10{ }^{\circ} \mathrm{C}$ outside (see Fig. 7). When focusing

Fig. 6 Topography and absolute energy consumption on route (a) and route (b) from Passauerhof to Maria Gugging

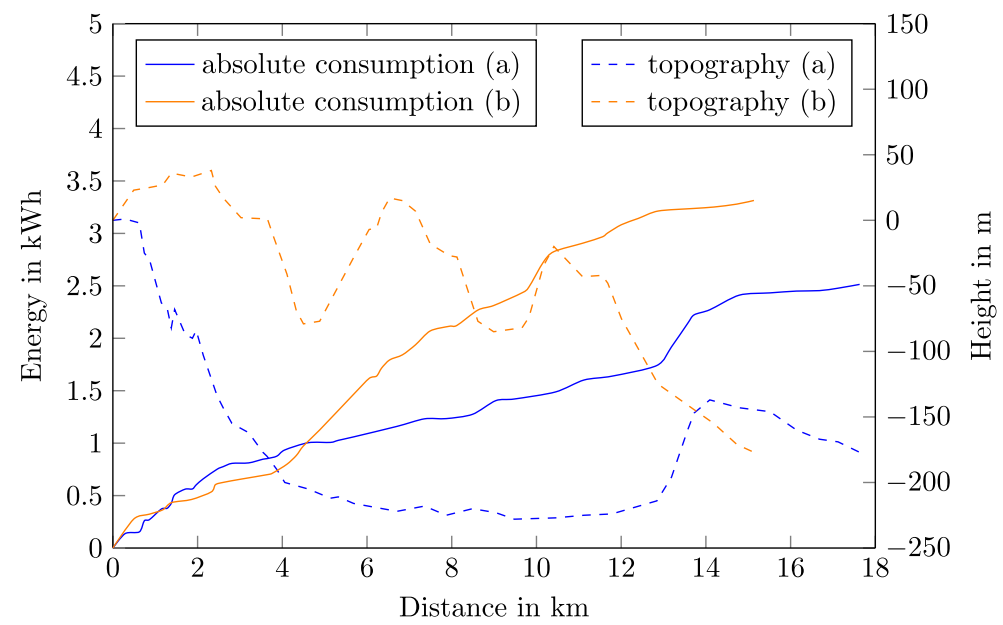


Table 3 Results from Passauerhof to Maria Gugging with different outside temperatures $\left(20^{\circ} \mathrm{C}\right.$-top; $-10^{\circ} \mathrm{C}$-bottom $)$

\begin{tabular}{lllllll}
\hline$\gamma / \delta$ & 0 & 0.2 & 0.4 & 0.6 & 0.8 & 1 \\
\hline 0 & $($ a) & (a) & (a) & (b) & (b) & (b) \\
0.2 & (a) & (a) & (a) & (b) & (b) & - \\
0.4 & (a) & (a) & (b) & (b) & - & - \\
0.6 & (a) & (a) & (b) & - & - & - \\
0.8 & (a) & (b) & - & - & - & - \\
1 & (a) & - & - & - & - & - \\
0 & (a) & (a) & (b) & (b) & (b) & (b) \\
0.2 & (a) & (a) & (b) & (b) & (b) & - \\
0.4 & (a) & (b) & (b) & (b) & - & - \\
0.6 & (b) & (b) & (b) & - & - & - \\
0.8 & (b) & (b) & - & - & - & - \\
1 & (b) & - & - & - & - & - \\
\hline
\end{tabular}

different routes highlighted in bold

on the cyclic lifetime of the battery only (low $\gamma$ and $\delta$ ), route (a) is still chosen because of the topography, as explained previously. Figure 8 shows that the cumulated absolute energy consumption and regeneration of route (a) is still smaller than that of route (b), but with a narrower margin at $-10^{\circ} \mathrm{C}$ compared with $20{ }^{\circ} \mathrm{C}$.

\section{Comparing two different types of electric vehicles}

So far, the tests are performed exclusively with the Nissan Leaf. In the following part, the Mitsubishi i-MiEV vehicle is added, assuming its characteristics as given in Table 1. The Mitsubishi vehicle is almost $30 \%$ lighter in weight than the Nissan, but its $c_{w}$-value is higher and its efficiencies are lower. In Table 4, the results for the Nissan Leaf and Mitsubishi i-MiEV are compared.

Figure 9 shows that the energy consumption on both routes, (a) and (b), is higher for the Mitsubishi despite having less weight. Another finding is that on both routes the cumulated absolute value (Fig. 10) of the consumed and regenerated energy of the Mitsubishi is smaller compared to Nissan. This result shows that the Mitsubishi regenerates less energy. Only once does the result change compared to the Nissan, which is for $\gamma=0.2$ and $\delta=0.4$. The absolute energy has the weight of $1-(\gamma+\delta)=0.4$. In this case, the objective to be minimized in (27) is almost equal for both routes, but with route (b) being slightly more efficient.

\section{Urban area: San Francisco, CA}

Further tests are conducted for the city of San Francisco, CA, because of its interesting topography. The street network of San Francisco is fundamentally different from the street network of Wienerwald, Austria. It is an urban area with a high road density. The network is a grid of perpendicular streets. Each intersection represents a node of the network. Because of the high road density, there is also a high number of nodes. Therefore, only a small part of downtown San Francisco is selected in order to keep the network more compact.
Fig. 7 Energy consumption (cumulated) on route (a) and route (b) from Passauerhof to Maria Gugging for different outside temperatures, $20^{\circ} \mathrm{C}$ and $-10^{\circ} \mathrm{C}$

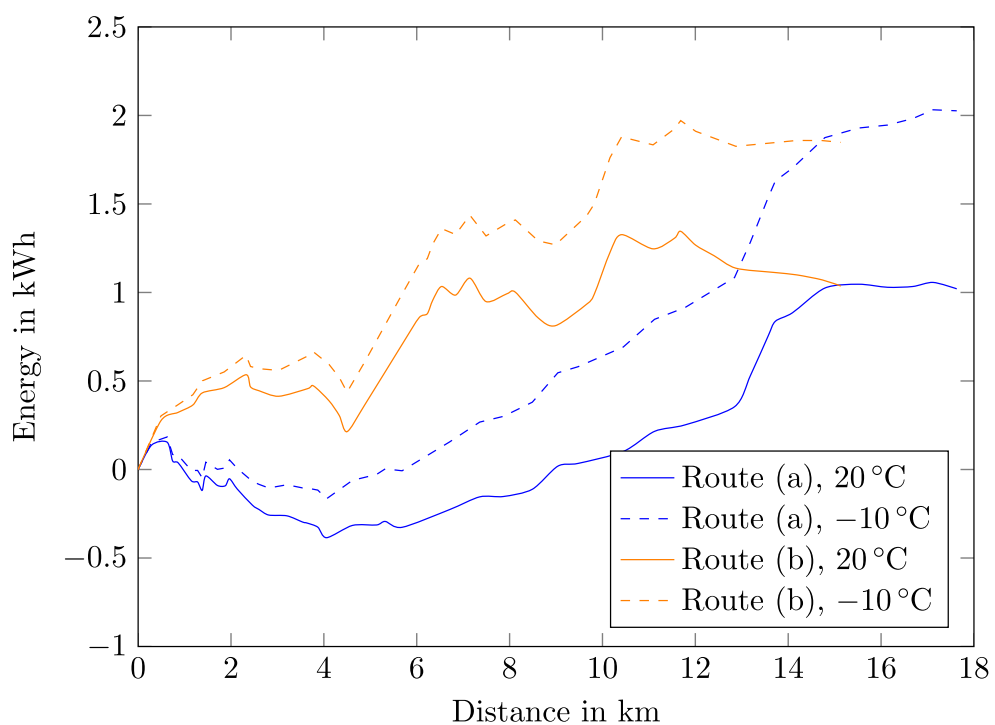


Fig. 8 Absolute value (cumulated) of the energy consumed or regenerated on route (a) and route (b) from Passauerhof to Maria Gugging for different outside temperatures, $20^{\circ} \mathrm{C}$ and $-10^{\circ} \mathrm{C}$

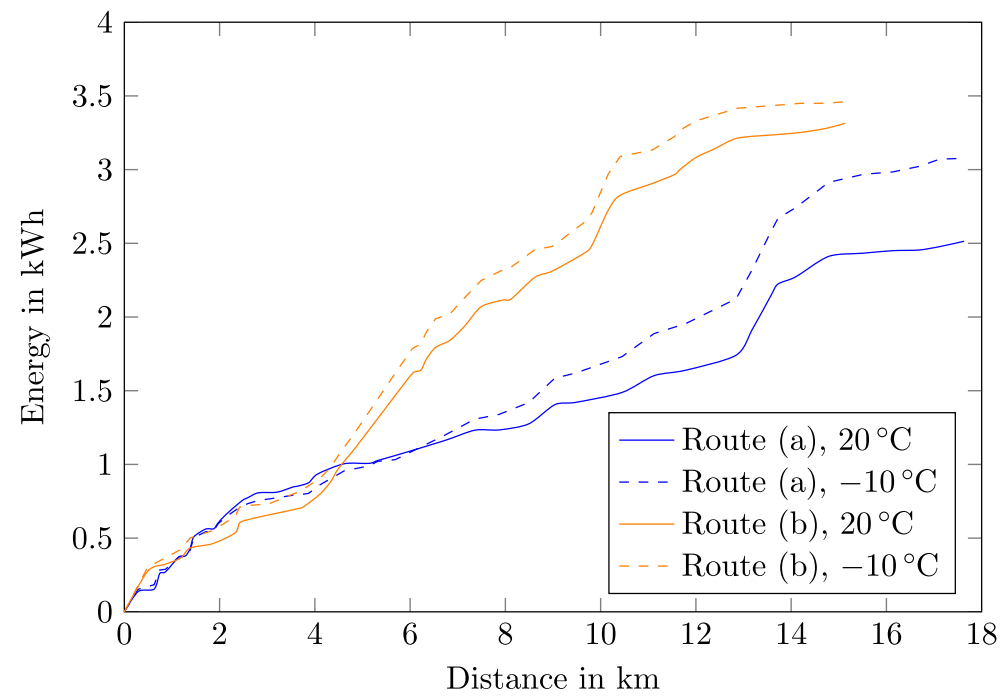

Modeling an urban street network may be challenging because there are many factors that are hard to predict. Traffic flow is on top of the agenda in this context. When searching for the fastest route, the current traffic situation and the timing of traffic lights are main concerns, other factors among many others may

Table 4 Results from Passauerhof to Maria Gugging for two different vehicle types (Nissan Leaf - top; Mitsubishi i-MiEVbottom) at $20{ }^{\circ} \mathrm{C}$

\begin{tabular}{lllllll}
\hline$\gamma / \delta$ & 0 & 0.2 & 0.4 & 0.6 & 0.8 & 1 \\
\hline 0 & (a) & (a) & (a) & (b) & (b) & (b) \\
0.2 & (a) & (a) & (a) & (b) & (b) & - \\
0.4 & (a) & (a) & (b) & (b) & - & - \\
0.6 & (a) & (a) & (b) & - & - & - \\
0.8 & (a) & (b) & - & - & - & - \\
1 & (a) & - & - & - & - & - \\
0 & (a) & (a) & (a) & (b) & (b) & (b) \\
0.2 & (a) & (a) & (b) & (b) & (b) & - \\
0.4 & (a) & (a) & (b) & (b) & - & - \\
0.6 & (a) & (a) & (b) & - & - & - \\
0.8 & (a) & (b) & - & - & - & - \\
1 & (a) & - & - & - & - & - \\
\hline
\end{tabular}

different routes highlighted in bold be being zebra crossings, stop signs, and bus stops. They influence not only the journey time but also the energy consumption. Nevertheless, the impacts of traffic and road signs are neglected for simplification in the present work. The focus is on the energy consumption and battery lifetime, which are expected to be considerably impacted by the topography of the city. Multi-objective optimization is performed with $\delta=0$.

\section{Route: from Pier 39 to Russian Hill}

Different starting and destination points are tested. One journey starts close to Pier 39, at the corner Beach Street/Grant Avenue. The destination point is Union Street/Hyde Street, close to Russian Hill. All combinations of the multi-objective optimization weights result in the same route (see Fig. 11). Going in the opposite direction, from Russian Hill to Pier 39 , gives the result seen in Fig. 12, for all values of $\gamma$.

Figure 13 (dashed lines) shows the topography of the two scenarios: Going from Pier 39 to Russian Hill (Union/Hyde Street) and the return. The energy consumption on both trips (see Fig. 13) strongly depends on the topography. Since Pier 39 is almost at sea level, going to Russian Hill takes a lot of energy, while the electric vehicle regenerates energy by going in the 
Fig. 9 Energy consumption (cumulated) on route (a) and route (b) from Passauerhof to Maria Gugging comparing Nissan Leaf and Mitsubishi i-MiEV at $20^{\circ} \mathrm{C}$

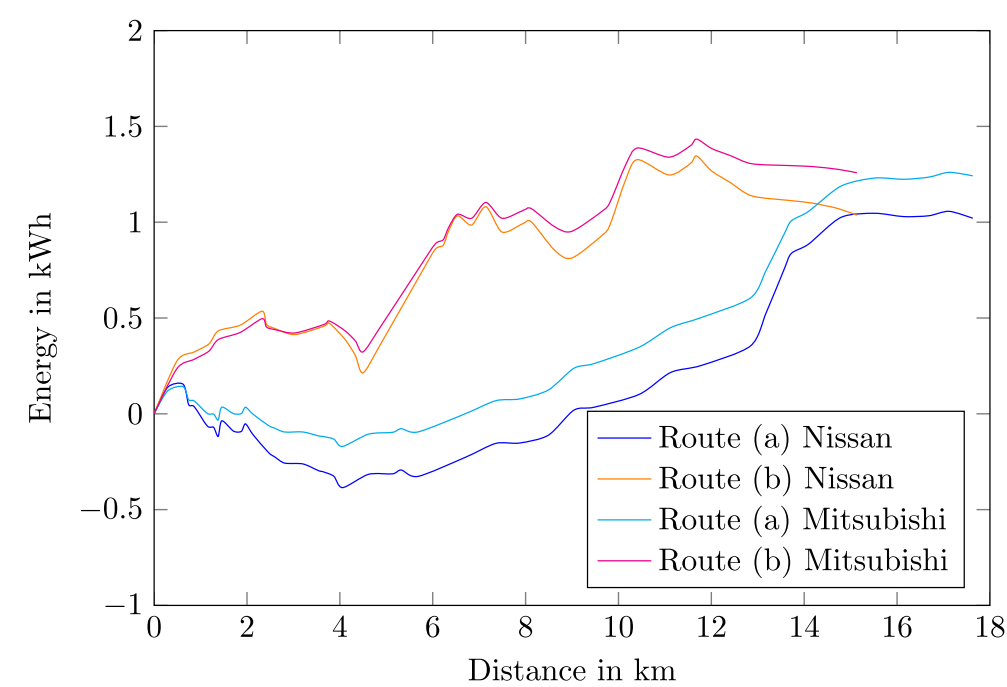

opposite direction down to Pier 39. In Fig. 14, it can be seen that the absolute energy flow of the return trip is a lot smaller.

Further results of San Francisco show that focusing on the battery lifetime often results in routes differing from those focusing on energy efficiency. Switching the destination point to another one close to the original results in the three routes represented in Fig. 15.
Figures 16 and 17 show the topography as well as the energy consumption and absolute energy consumption of the three results. Route (a) is the result for $\gamma=0$ and $\gamma=0.2$. It is longer and not as energy efficient as route (b) and (c), but shows better performance in terms of battery lifetime due to a different topography. Route (c) is the most energy efficient route $(\gamma=0.8$ and $\gamma=1)$.
Fig. 10 Absolute value (cumulated) of the energy consumed or regenerated on route (a) and route (b) from Passauerhof to Maria Gugging comparing Nissan Leaf and Mitsubishi i-MiEV at $20^{\circ} \mathrm{C}$

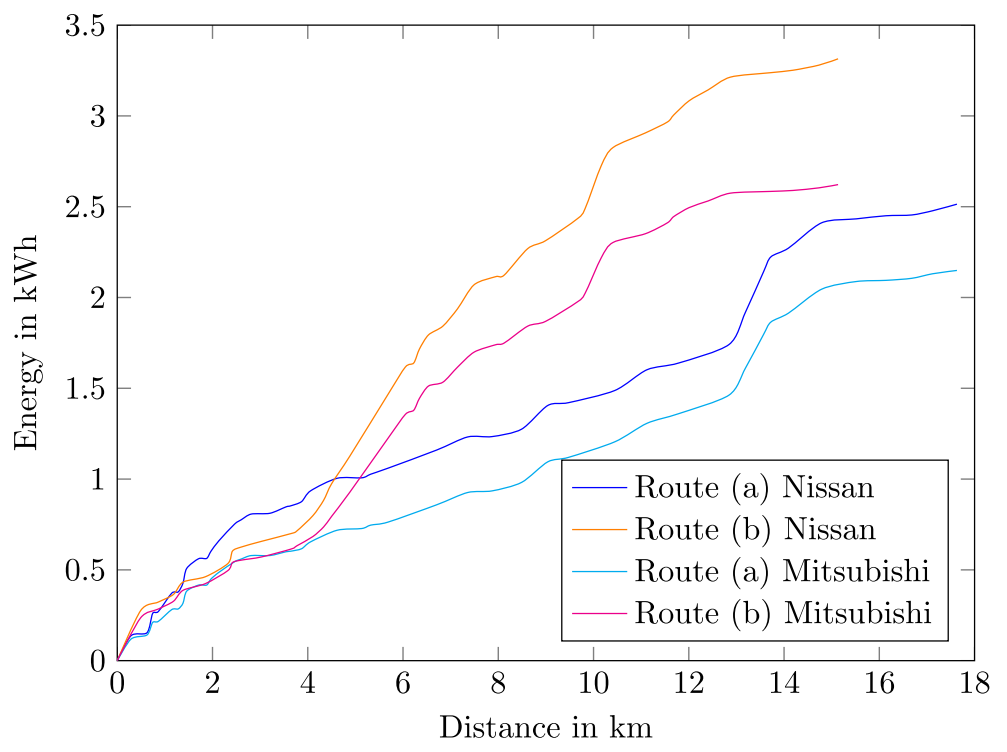




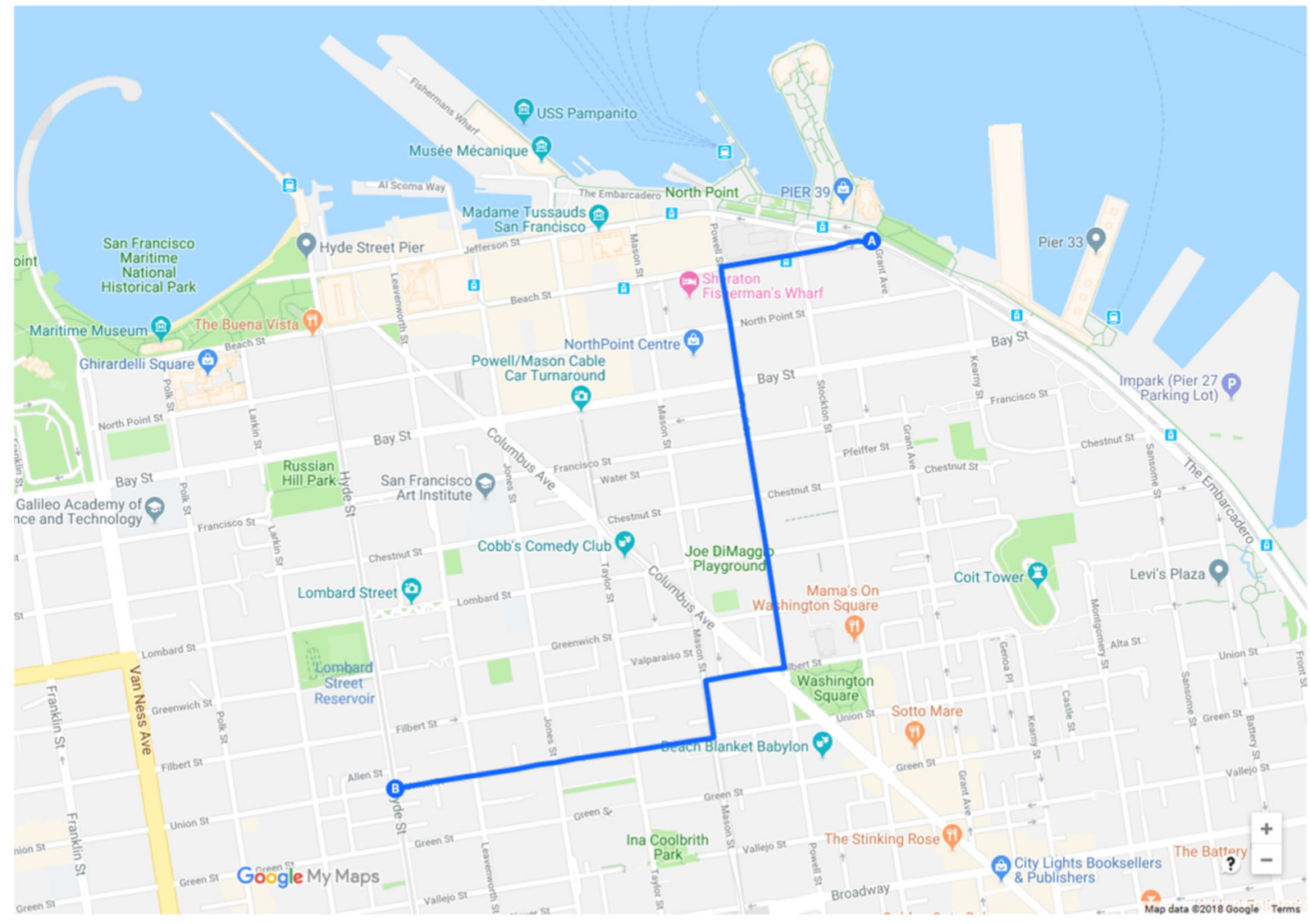

Fig. 11 Results from Pier 39 to Russian Hill (screen-shot from Google Maps—Google and the Google logo are registered trademarks of Google LLC, used with permission)

\section{Conclusion and outlook}

This work shows that route planning specifically designed for electric vehicles has more to offer than conventional routing systems, which only consider time or distance to the destination. The multiobjective optimization has three aspects : energy consumption, journey time, and battery lifetime. With different weights on the optimization variables, different solutions are obtained. Tests are performed for existing street networks. In some cases, there is only one optimal route for all variables, while other cases show very distinct results for one of the optimization variables.

The results demonstrate the influence of the topography on the routes. The energy consumption depends significantly on the topography. Especially with electric vehicles, which may regenerate energy by driving downhill, there is a strong correlation between energy consumption and topography. The third aspect of the multi-objective optimization is to increase the battery lifetime. The approach in this paper evaluates battery degradation by minimizing the total energy flow of the battery and therefore the number of charging cycles over the battery's lifetime, which is different to arriving at the destination with the highest state of charge possible, which is essentially the first aspect of the multi-objective optimization. Routes with high topographical variation increase stress on the battery and are therefore avoided with focus on the battery lifetime. The battery is an expensive part and key element of the vehicle and, as such, should be protected from degradation as much as possible. The influence of additional loads such as heating, air condition, lights, and fan is significant. Those loads are powered by the battery and therefore increase the total energy consumption, with an important factor being the duration of the journey, as more energy is used the longer these 


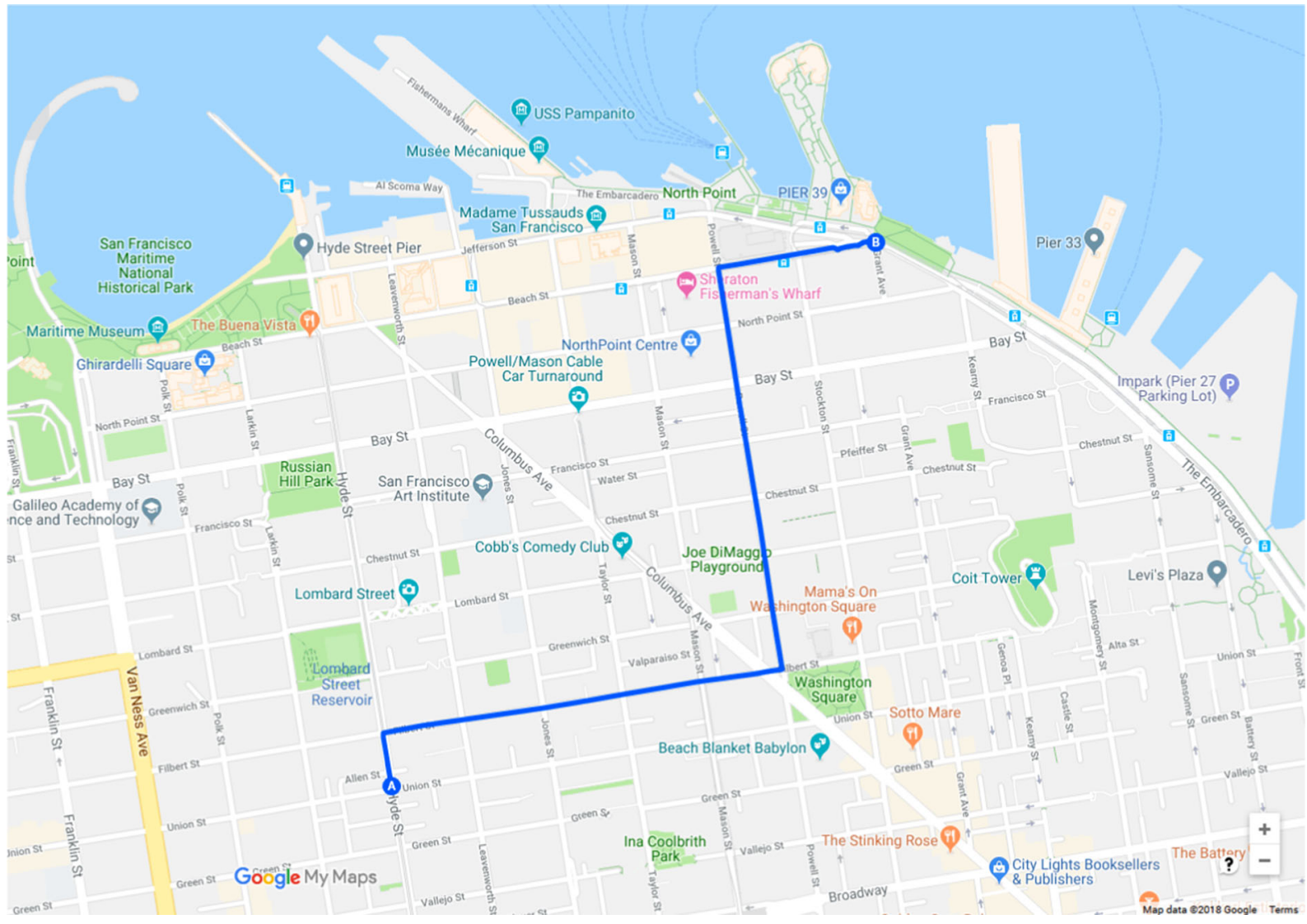

Fig. 12 Results from Russian Hill to Pier 39 (screen-shot from Google Maps-Google and the Google logo are registered trademarks of Google LLC, used with permission)

Fig. 13 Topography and energy consumption from Pier 39 to Russian Hill and back

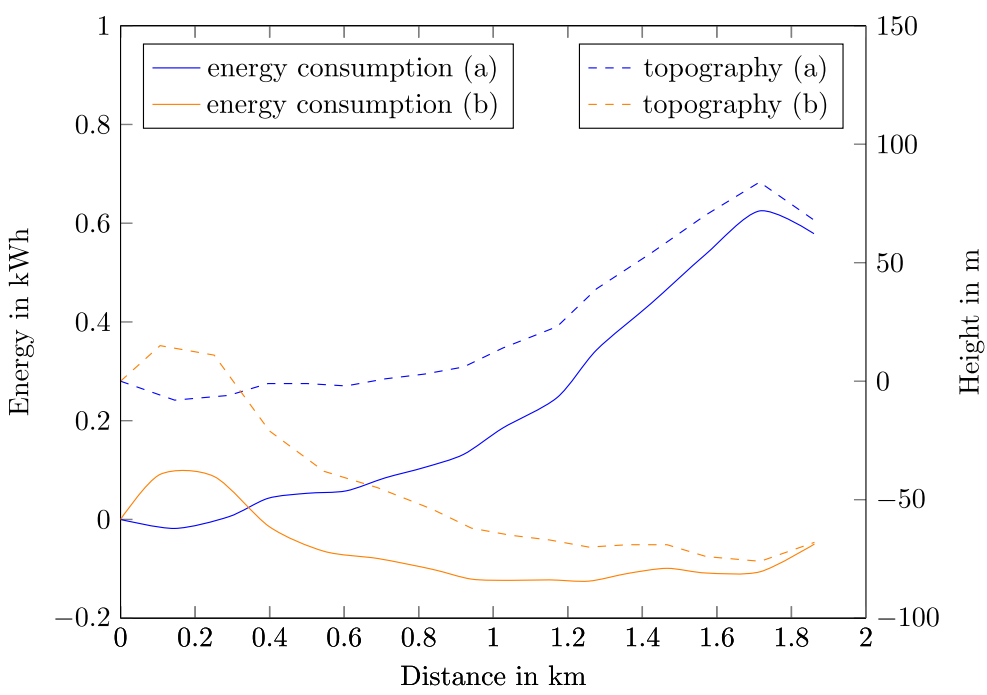


Fig. 14 Topography and absolute energy consumption from Pier 39 to Russian Hill and back

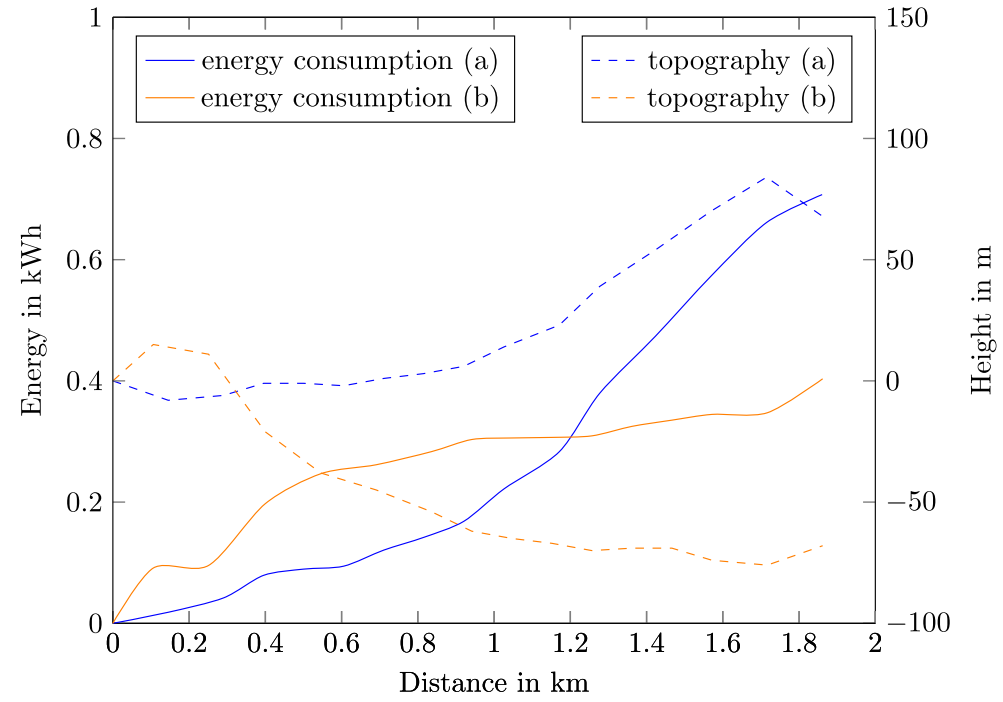

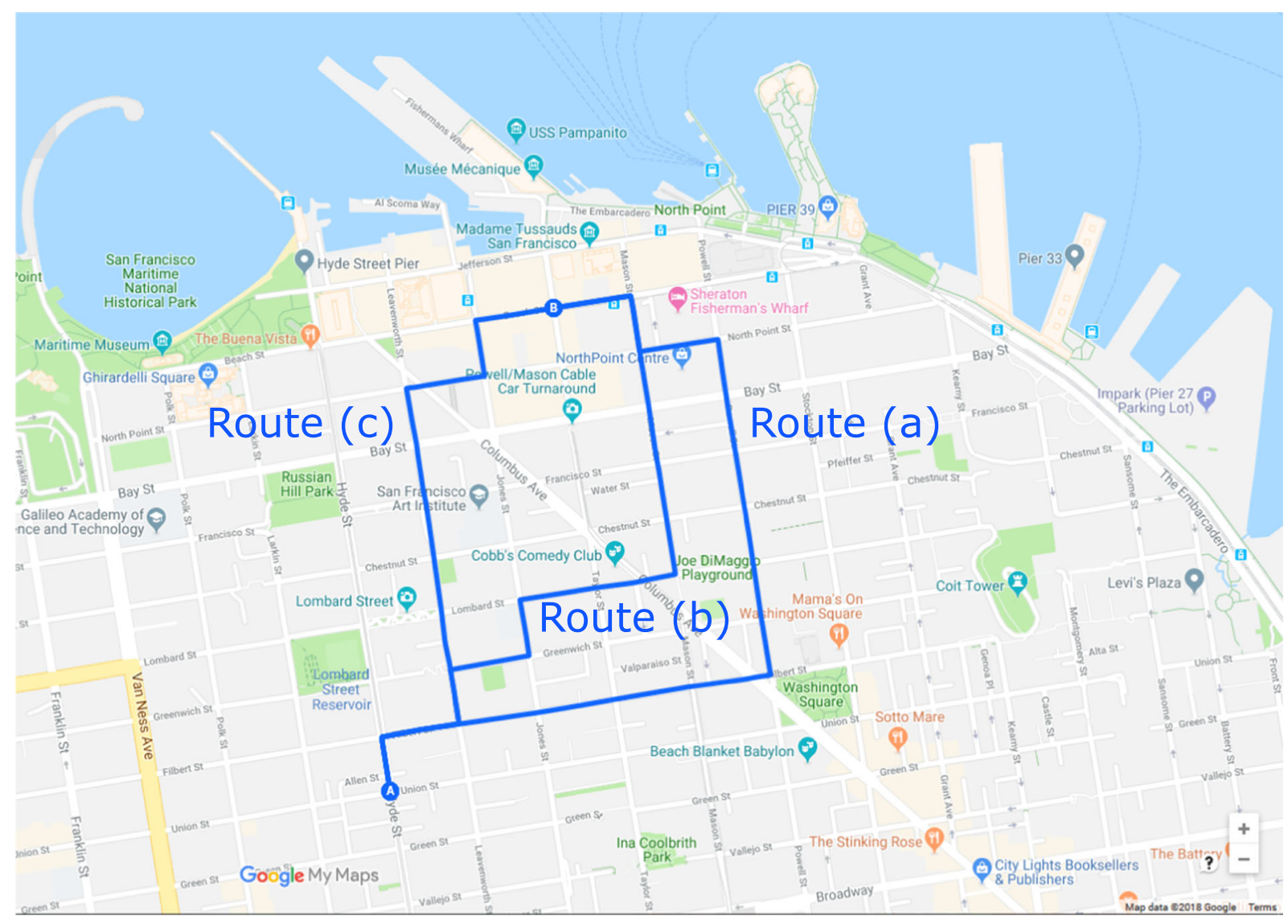

Fig. 15 Route options (a), (b), and (c) in San Francisco (edited screen-shot from Google Maps; Google and the Google logo are registered trademarks of Google LLC, used with permission) 
Fig. 16 Topography and energy consumption for route options (a), (b), and (c) in San Francisco

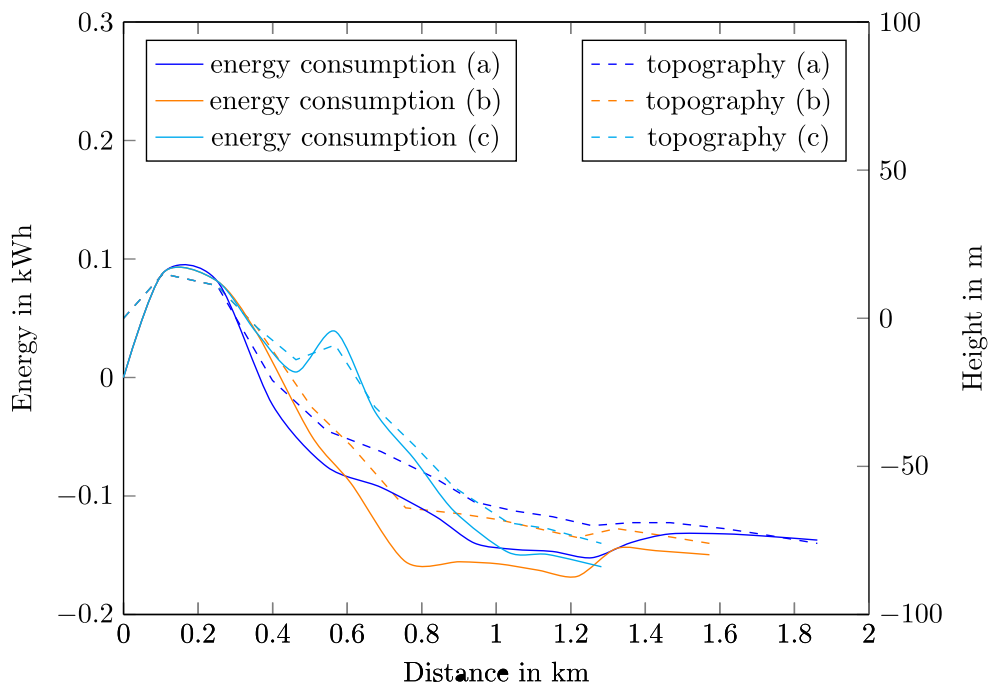

additional loads operate. Accordingly, the results of the multi-objective optimization may change, due to fast routes becoming more energy efficient.

Using a weighted multi-objective optimization may be more reasonable than using a single-objective optimization. If the second fastest route were much more energy efficient, but only slightly slower than the fastest route, a time-only optimization leads to an unreasonable result, but when different aspects are considered at the same time, the most practical solution is achieved. In order to use this type of route planning for real-world scenarios, more accurate street data is necessary as well as some additional information: Traffic lights and stop signs should be included, as well as traffic flow, as a theoretically optimal route may in practice prove to be infeasible due to traffic holdups. Integration of the multi-objective optimization algorithm (knowing vehicle type and ambient conditions) into existing route planning systems with better street data could be an addition appreciated by EV owners. Future work on this topic should also include charging stations such that route planning is possible for a journey farther than the battery range of the vehicle.
Fig. 17 Topography and absolute energy consumption for route options (a), (b), and (c) in San Francisco

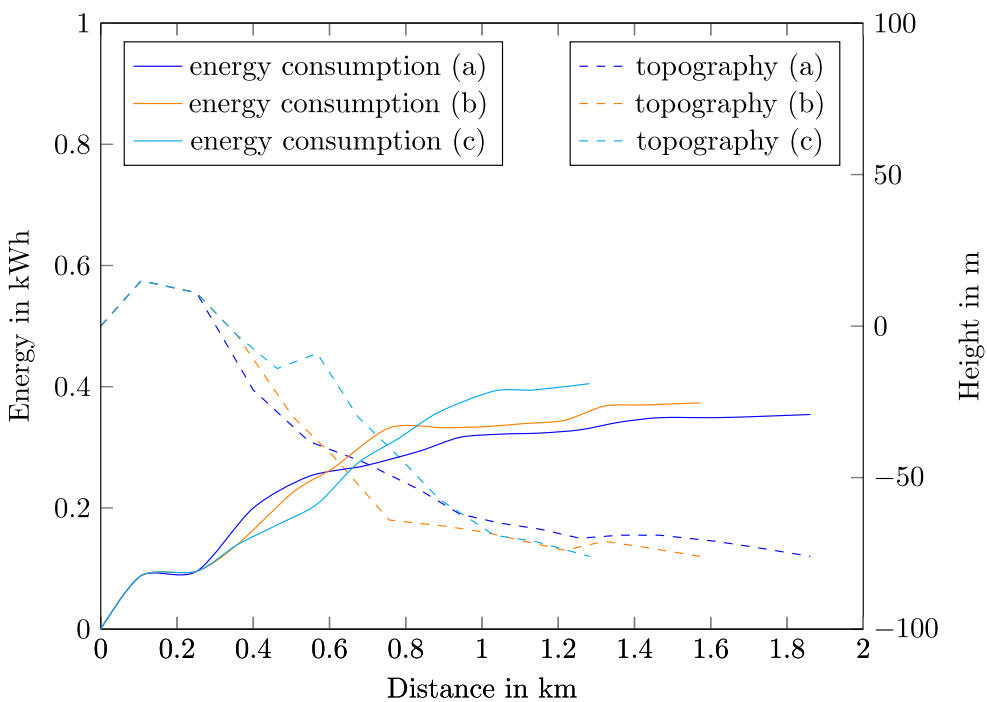


Lastly, another important aspect to be included in future work is driving behavior. Speed and acceleration influence the energy consumption of the vehicle. In urban areas, the journey time is mainly dependent on the traffic situation rather than the speed, while in non-urban areas the speed may have a significant impact. Assuming a certain speed profile could help achieving realistic results. Either a statistical approach to obtain a speed profile, or learning from previously obtained data of the driver's preferences could be utilized.

Funding Open access funding provided by TU Wien (TUW).

\section{Compliance with ethical standards}

Conflict of interest The authors declare that they have no conflict of interest.

Open Access This article is licensed under a Creative Commons Attribution 4.0 International License, which permits use, sharing, adaptation, distribution and reproduction in any medium or format, as long as you give appropriate credit to the original author(s) and the source, provide a link to the Creative Commons licence, and indicate if changes were made. The images or other third party material in this article are included in the article's Creative Commons licence, unless indicated otherwise in a credit line to the material. If material is not included in the article's Creative Commons licence and your intended use is not permitted by statutory regulation or exceeds the permitted use, you will need to obtain permission directly from the copyright holder. To view a copy of this licence, visit http:// creativecommonshorg/licenses/by/4.0/.

\section{Appendix 1. Time-optimal route planning}

Compared with the search for an energy-optimal path, finding a time-optimal path is a lot less complicated. On the one hand, there are no constraints assumed concerning the journey time. It is just about finding the fastest itinerary. On the other hand, there are no negative edge costs. In fact, the graph is undirected if it is assumed that the same road with the same speed limit is available for the way back. This optimization problem could be solved with a less complex and faster algorithm than Bellman-Ford or Yen, because there are no negative edge costs. Although, when energy and time are combined to multi-objective optimization, it is easier to just use the same algorithm, because the computation time is not crucial in this work. The procedure is the same as for finding an energy-optimal path. In this case, the edge costs represent the journey time. The journey time of an edge connecting node $i$ and $j$ is the sum of $M$ adjacent road sections

$t_{i j}=\sum_{l=1}^{M} t_{l}$,

with each road section having a designated speed level $v_{l}$ and the length $s_{l}$ :

$t_{l}=v_{l} / s_{l}$.

Iteration 0 is given as

$g_{i}^{(0)}=t_{1 i}$,

where $t_{1 i}$ are the edges costs from node 1 to node $i=$ $2, \ldots, N$. For odd iterations, the minimum is found using

$$
\begin{array}{r}
g_{i}^{(2 k-1)}=\min _{1 \leq j<i}\left(g_{j}^{(2 k-1)}+t_{j i}, g_{i}^{(2 k-2)}\right), \\
g_{1}^{(2 k-1)}=g_{1}^{(2 k-2)},
\end{array}
$$

with $i=2,3, \ldots, N$. For even iterations, the minimization is

$$
\begin{array}{r}
g_{i}^{(2 k)}=\min _{N \geq j>i}\left(g_{j}^{(2 k)}+t_{j i}, g_{i}^{(2 k-1)}\right), \\
g_{N}^{(2 k)}=g_{N}^{(2 k-1)},
\end{array}
$$

with $i=N-1, N-1, \ldots, 2$.

\section{Appendix 2. Energy-optimal route planning in order to increase battery lifetime}

The third criterion, which may be used for route planning is increasing battery lifetime. Battery wear-off should be avoided for as long as possible, as it can decrease the capacity as well as limit the range of the vehicle. The battery is also a very expensive part of the electric vehicle to replace. There are some actions to be taken in order to increase the battery lifetime. First, avoiding deep discharge is helpful. This can be included in the factor $a$, which can be tuned to a value that is safe for the battery.

A lithium-ion battery, which is the power source for most electric vehicles, usually has a specific cyclic lifetime. Decreasing the total number of cycles of the battery helps to increase its lifetime. This is the third criterion of the multi-objective optimization. It is performed in a similar way as the energy-optimal planning, but takes the absolute value of the energy 
as the edge costs. Power provided by the battery for driving or for accessories is treated the same as regenerated energy from braking and driving downhill, thus increasing the costs instead of decreasing them. The edge costs from node $i$ to $j$ is $a_{i j}$, the sum of the absolute energy values of all road sections belonging to this edge. Similar to (A1.1), $a_{i j}$ is calculated

$a_{i j}=\sum_{l=1}^{M} a_{l}$,

with $a_{l}=\left|E_{l}\right| . h_{i}$ are the costs from node 1 to node $i$. Iteration 0 is given as

$h_{i}^{(0)}=a_{1 i}$,

where $a_{1 i}$ are the edges costs from node 1 to node $i=$ $2, \ldots, N$. For odd iterations, the minimum is found using

$$
\begin{array}{r}
h_{i}^{(2 k-1)}=\min _{1 \leq j<i}\left(h_{j}^{(2 k-1)}+a_{j i}, h_{i}^{(2 k-2)}\right), \\
h_{1}^{(2 k-1)}=h_{1}^{(2 k-2),}
\end{array}
$$

with $i=2,3, \ldots, N$. For even iterations, the minimization is

$$
\begin{array}{r}
h_{i}^{(2 k)}=\min _{N \geq j>i}\left(h_{j}^{(2 k)}+a_{j i}, h_{i}^{(2 k-1)}\right), \\
h_{N}^{(2 k)}=h_{N}^{(2 k-1)},
\end{array}
$$

with $i=N-1, N-1, \ldots, 2$.

\section{References}

Bellman, R. (1958). On a routing problem. Quarterly of Applied Mathematics, 16(1), 87-90. https://doi.org/10.1090/qam/ 102435.

Dijkstra, E.W. (1959). A note on two problems in connexion with graphs. Numerische Mathematik, 1(1), 269-271. https://doi.org/10.1007/BF01386390.

Fernández, I., Calvillo, C., Sánchez-Miralles, A., Boal, J. (2013). Capacity fade and aging models for electric batteries and optimal charging strategy for electric vehicles. Energy, 60, 35-43. https://doi.org/10.1016/j.energy.2013. 07.068.

Geringer, B., \& Tober, W.K. (2012). Batterieelektrische Fahrzeuge in der Praxis. Tech. rep., Institut für Fahrzeugantriebe und Automobiltechnik, Technische Universität Wien.

Gota, S., Huizenga, C., Peet, K., Medimorec, N., Bakker, S. (2019). Decarbonising transport to achieve paris agreement targets. Energy Efficiency, 12(2), 363-386. https://doi.org/ 10.1007/s12053-018-9671-3.
Haken, K.L. (2013). Grundlagen der Kraftfahrzeugtechnik, 3rd edn. München: Carl Hanser.

Hawkins, T.R., Singh, B., Majeau-Bettez, G., Strømman, A.H. (2012). Comparative environmental life cycle assessment of conventional and electric vehicles. Journal of Industrial Ecology, 17(1), 53-64. https://doi.org/10.1111/j.1530-92 90.2012.00532.x.

Hayes, J.G., de Oliveira, R.P.R., Vaughan, S., Egan, M.G. (2011). Simplified electric vehicle power train models and range estimation. In 2011 IEEE Vehicle Power and Propulsion Conference (pp. 1-5). https://doi.org/10.1109/VPPC. 2011.6043163.

Jeschke, S. (2016). Grundlegende Untersuchungen von Elektrofahrzeugen im Bezug auf Energieeffizienz und EMV mit einer skalierbaren Power-HiL-Umgebung universität Duisburg-Essen.

Johnson, D.B. (1977). Efficient algorithms for shortest paths in sparse networks. Journal of the ACM, 24(1), 1-13. https://doi.org/10.1145/321992.321993.

Li, H., Alsolami, M., Yang, S., Alsmadi, Y.M., Wang, J. (2017). Lifetime test design for second-use electric vehicle batteries in residential applications. IEEE Transactions on Sustainable Energy, 8(4), 1736-1746. https://doi.org/10.1109/ TSTE.2017.2707565.

Lv, C., Zhang, J., Li, Y., Yuan, Y. (2015). Mechanism analysis and evaluation methodology of regenerative braking contribution to energy efficiency improvement of electrified vehicles. Energy Conversion and Management, 92, 469-482. https://doi.org/10.1016/j.enconman.2014.12.092.

Maia, R., Silva, M., Araújo, R., Nunes, U. (2011). Electric vehicle simulator for energy consumption studies in electric mobility systems. In 2011 IEEE Forum on Integrated and Sustainable Transportation Systems (pp. 227-232). https://doi.org/10.1109/FISTS.2011.5973655.

MATLAB (2019). (R2019b). The MathWorks Inc., Natick, Massachusetts.

Mitsubishi: https://www.mitsubishi-motors.com/en/showroom/ i-miev/specifications.

Neaimeh, M., Hill, G.A., Hübner, Y., Blythe, P.T. (2013). Routing systems to extend the driving range of electric vehicles. IET Intelligent Transport Systems, 7(3), 327-336. https:// doi.org/10.1049/iet-its.2013.0122.

Nissan: https://www.nissan.co.uk.

Nunzio, G.D., \& Thibault, L. (2017). Energy-optimal driving range prediction for electric vehicles. In 2017 IEEE Intelligent Vehicles Symposium (IV) (pp. 1608-1613). https://doi. org/10.1109/IVS.2017.7995939.

Pelletier, S., Jabali, O., Laporte, G., Veneroni, M. (2017). Battery degradation and behaviour for electric vehicles: Review and numerical analyses of several models. Transportation Research Part B: Methodological, 103, 158-187. https://doi.org/10.1016/j.trb.2017.01.020. Green Urban Transportation.

Peterson, S.B., Apt, J., Whitacre, J. (2010). Lithium-ion battery cell degradation resulting from realistic vehicle and vehicleto-grid utilization. Journal of Power Sources, 195(8), 23852392. https://doi.org/10.1016/j.jpowsour.2009.10.010.

Rizoug, N., Mesbahi, T., Sadoun, R., Bartholomeüs, P., Le Moigne, P. (2018). Development of new improved 
energy management strategies for electric vehicle battery/supercapacitor hybrid energy storage system. Energy Efficiency, 11(4), 823-843. https://doi.org/10.1007/s120 53-017-9602-8.

Song, Z., Duan, H., Zhou, S., Qiu, X. (2015). Urban route planning considering traffic flows. In: 2015 Chinese Automation Congress (CAC), pp. 1940-1944. https://doi.org/10.11 09/CAC.2015.7382822.

Storandt, S. (2012). Route planning for bicycles - exact constrained shortest paths made practical via contraction hierarchy. In: Twenty-second international conference on automated planning and scheduling.

Storandt, S., Eisner, J., Funke, S. (2013). Enabling e-mobility: One way, return, and with loading stations. In: 27th AAAI Conference on Artificial Intelligence.

Storandt, S., \& Funke, S. (2012). Cruising with a batterypowered vehicle and not getting stranded. In: 26th AAAI Conference on Artificial Intelligence.

USGS: Usgs earthexplorer. https://earthexplorer.usgs.gov/. Accessed 2018-02-24.
Wang, D., Coignard, J., Zeng, T., Zhang, C., Saxena, S. (2016). Quantifying electric vehicle battery degradation from driving vs. vehicle-to-grid services. Journal of Power Sources, 332, 193-203. https://doi.org/10.1016/j.jpowsour. 2016.09.116.

Yen, J.Y. (1970). An algorithm for finding shortest routes from all source nodes to a given destination in general networks. Quarterly of Applied Mathematics, 27(1), 526-530. https://doi.org/10.1090/qam/253822.

Yi, Z., \& Bauer, P.H. (2017). Adaptive multiresolution energy consumption prediction for electric vehicles. IEEE Transactions on Vehicular Technology, 66(11), 10515-10525. https://doi.org/10.1109/TVT.2017.2720587.

Publisher's note Springer Nature remains neutral with regard to jurisdictional claims in published maps and institutional affiliations. 